\section{Heidegger, Ethics, and Animals}

\author{
Bruce V. Foltz \\ Eckerd College
}

Editors' Note: The following article by

Professor Foltz and commentary by

Professor Jean Kuebler were presented at the Eastern Division meeting of the Society for the Study of Ethics and Animals, held in Washington, D.C., December 28, 1992.

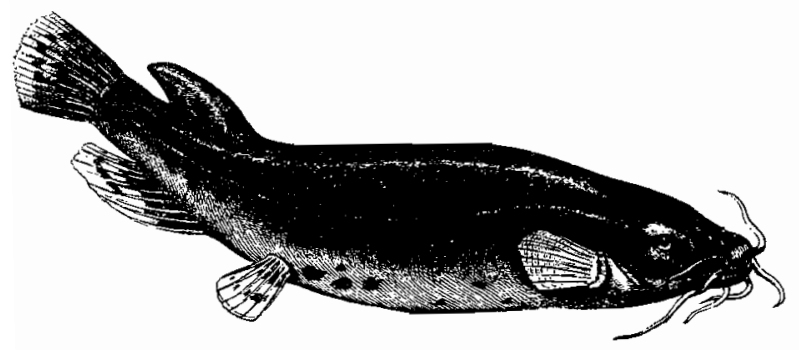

At first glance, the work of Martin Heidegger would seem to be an unlikely source for ethical reflection on our relation to animals. First, it has long been regarded as problematical that Heidegger-whose work seems otherwise to have a comprehensive scope-did not write an "ethics" in the modern sense of the term, i.e., did not arrive at a theory of moral obligation on the model of Kant or Mill or his own compatriot and early animal rights advocate, Leonard Nelson. Second, Heidegger's published works-including his recently published lectures, lecture courses, and seminars in the German Collected Works-say virtually nothing about how animals in particular ought to be treated. Third, when he does discuss animals, his purpose is usually to argue vigorously for a fundamental difference between them and human beings, even maintaining that there is an ontological "abyss" between humans and animals.

There is, however, a countervailing consideration. Although his writings are not often actually read within the field, Heidegger has begun to be cited so often in the literature of deep ecology that he may be said to have attained a semi-canonical status, and the interestand secondary literature-in the relation between Heidegger and deep ecology are beginning to proliferate

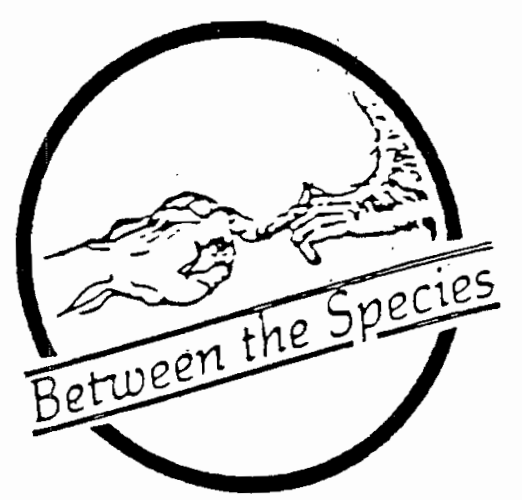

prodigiously. Put simply, it is being argued that Heidegger (a) provides an analysis and diagnosis of Western thought and culture, and a critique of modern technology, which taken together allow us to understand why we are faced with the present environmental crisis, and (b) that he shows ways of drawing upon different possibilities inherent in Western thought and cultureasking us neither to take up the practice of Taoism, nor to embrace Native American cosmogonies- that would lead to a far more salutary relation between humankind and the natural world. And although there have been historic tensions between the "deep ecology" and "animal rights" emphases in environmental ethics, any views prescribing a fundamental alteration in our relation to the natural environment must still be assumed prima facie to hold important implications for our treatment of animals.

Working from this latter point of view, I shall today argue first, that rather than neglecting the subject, Heidegger's thinking offers us the elements for an alternative understanding of ethics that is especially well suited to the task of finding better ways of getting along with other residents of this planet. Second, I shall maintain that although Heidegger offers no specific prescriptions regarding our treatment of animals, there are some things that we can extrapolate from his writings with confidence. Third, I shall propose that Heidegger's work provides us with a good occasion to

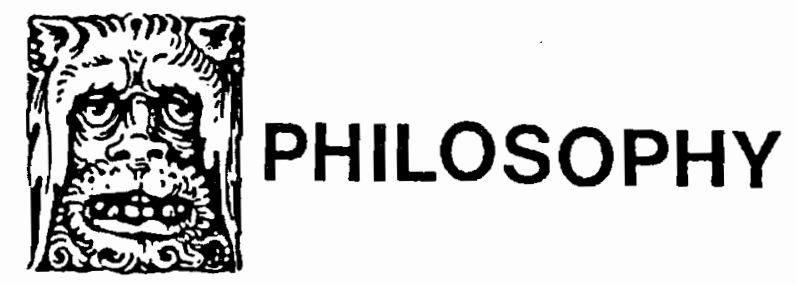


question the widely held views that fundamental distinctions drawn between humans and animals lead to the mistreatment of animals, and correspondingly, that maintaining the absence of radical difference is necessarily conducive to the welfare of animals.

\section{Heidegger's Question of Being and Its Implications for Ethics}

In order to see what kind of ethics might follow from Heidegger's thought, it is necessary to proceed from his concen for what the tradition has termed "ontology." To simplify matters a great deal, Heidegger can be seen as challenging the entire sense of being - the entire sense and experience of what it means to say that something or someone "is"-which has come to predominate in the West. Beginning with the ancient Greeks, and progressing until the present time, we have overemphasized "presence" and transparency as a model for comprehension, while underemphasizing and even castigating absence and opacity. But while the Greeks valorized the clear and manifest purity of form (Plato) or the triumphant sway of the actual (Aristotle), for us today the Western thirst for presence takes the shape of a demand for objectivity in modern sciencethe status of being an object laid out for view by a (human) subject-and availability as a resource (and ultimately as a consumable inventory) in modern technology. Heidegger argues, then, that what counts for us as something that "is" is the scientific object and the technological stockpile.

In order to count for us today as having being - that is, as being something that is at all extant--an entity must be secured as either an object of scientific knowledge or, better yet, as a stored "resource" on call for eventual consumption or further production. Moreover, Heidegger sees this modern ontology as the outcome of a virtually inexorable progression that begins with the ancient Greeks: starting with Plato's vision of purely intelligible and eternally unchanging forms (that is, being as completely present and always present) and Aristotle's emphasis on actuality (that is, being as present as well in this and that entity), Western thought and existence has emphasized presence at the expense of absence. Against this, Heidegger maintains that the character of presence is not exhaustive of being, that absence and withdrawal and opacity are characters of being that are not only equiprimordial with presence but even possess a certain priority. The Greek word, for example, that we translate as truth is a-letheia: rendered literally, un-concealment or un-hiddenness, implying that prior to the onset of Greek philosophy and the metaphysics of presence, a primacy of hiddenness and concealment was acknowledged. Truth as unconcealment is always wrested away from a prior hiddenness (whether it be that of error, dissemblance, or oblivion) to which it is destined as well to return. Before, after, and in the midst of presence and clarity and intelligibility, Heidegger maintains, lies recalcitrance, withdrawal, darkness, mystery.

But does this not prove that Heidegger's critics are right in branding him a mystagogue and irrationalist? On the contrary, it calls for all the greater vigilance on the part of reason (that it not be seduced unknowingly by unreason) and passion in the quest for truth (that it must always again be fought for and won). Like Kant, Heidegger seeks to limit and define (rather than bound and restrict) reason and intelligibility; but whereas Kant fixed the recalcitrance of being in the noumenal realm, Heidegger wants us to note how it seeps into every kind of clarity and overtness-to see that overtmess is never total and explanation is never final, that mountains and people and rivers and animals are always more than what we make them out to be - and more than what we wish to make of them as well. Entities are always more than the uses we find for them, more than the lucidity of theory can reveal, more than experience can exhaust, and this is so not as a matter of fact but necessarily, inevitably. This view prescribes, if you will, a sort of ontological humility in the face of the integrity of beings, an ontological deference toward their resistance to being reduced to our knowledge of them and our uses for them, and above all their resistance to that allencompassing network of supply and regulation that is modern technology. Heidegger's German word for this comportment which lets entities be what they are, while at the same time relinquishing the claim of technology to determine the being of entities, is Gelassenheit.

"We are not dealing here with just any question," Socrates tells Glaucon at an important point in Plato's dialogue on justice, "but with the question of how life is to be lived." If we understand ethics not in its narrower, modern sense-as a theory of moral obligation-but in this broader sense of the ancientsas reflection on how life as a whole is to be livedthen Heidegger's Gelassenheit is as much an ethic as it is an epistemology. Gelassenheit is releasement-a letting-go that is at the same time a letting-be. Letting-go 
of technology and its ontological ambitions to bring entities into unhiddenness as stock and resource-not atavistically abandoning technology but letting-go of its compulsiveness and seductiveness, its claims to offer not just convenience but revelation and salvation-such a letting-go is a letting-be of entities: not a neglect or ignoring of them (just letting them alone) but a positive allowing of entities to be what they are, a clearing of space for beings to reveal themselves of their own accord, as well as to make manifest their resistance to total manifestation.

Such a comportment toward entities, as a manner of being-in-the-world amidst entities, can be characterized as a mode of inhabiting the world. And Heidegger maintains that this sense of a mode of inhabitation is in fact the primal and primary meaning of ethics, beginning with the Greek word ethos which derived its sense of "custom," "habit," and "character" from its earlier meanings of "accustomed place," and abode. Heidegger, then, opens up a new space for ethical thought by thinking ethics as ethos, i.e., as mode of dwelling or inhabitation, and by thinking Gelassenheit (releasement or letting-be) as a mode of what he calls in the "Letter on Humanism" "primal" or "original ethics," i.e., a dwelling or primary mode of comportment so basic that it would precede the distinction of theory and practice, and hence be as much a knowing as a doing - and vice versa. The most basic question of ethics is the question of how it is that we are to inhabit the world, the question of how we are to comport ourselves within the world-whether our primary bearing in relation to entities is to be one of self-assertive will to control and domination or one of pause and listening and letting-be.

\section{A Heideggerean Ethic of Dwelling, Saving, and Letting-be, and Its Implications for Our Treatment of Animals}

What implications would this have, then, for the question of how human beings ought to treat animals? How would this kind of thinking, were it to be embraced, alter our practices toward animals? Before dealing with this question, two brief qualifications are in order. First, we are not justified in expecting from Heidegger an ethical "theory" which we could then straightforwardly "apply" as a theoretical foundation for specific mnral judgments. That distance which thought would assume over against a world of objects, and that positing of foundations on the basis of which entities would be measured and judged, are both principal maneuvers of what Heidegger disavows as the "subjectivity" of modern thought which aims to master and dominate what it encounters. What is needed, rather, is a thoughtful dwelling in the midst of things, not the detachment of theoria which would set them up as objects-and ultimately, he argues, as resources.

Second, we should also note that after the political fiasco of his university rectorship during the early thirties, Heidegger refrained from making public pronouncements on specific social and moral issues, preferring instead to engage his thinking with issues at a more radical level of inquiry. In my view, this was a wise and happy decision, for it has served to free his thought from the stodgy, conservative, and provincial limits of his own biography and psychological makeup - a freeing which usually accrues to the work of major thinkers only after greater passage of time (think of the near century it took for Nietzsche's thought to come into its own) or a violent reshaping (think of the appropriation of Hegel by the Young Hegeleans and Marx). But at the same time, Heidegger's restraint puts us (as it should) on our own in exploring its practical implications. For better or worse Heidegger himself offers us as many specific prescriptions on how we should treat animals as he does on how we should treat other people, and that is precisely none at all.

This being said, we can with some caution extrapolate what we could term an onto-ethical imperative that is implicit in Heidegger's work, and even more cautiously, we could formulate it along the following lines: in our thinking, and speaking, and acting, to allow to those entities with which we concern ourselves those modes of coming-into-presence, as well as self-witholding and withdrawal, that they would show forth of their own accord. Parallel to St. Paul, Heidegger would seem to be telling us: "LET BE, and do what thou will." And like Kant, he would seem to be implying that we should treat always at the same time as an end and never merely as a means, but with an important difference, for the Heideggerean injunction would not be limited to persons-indeed, it would not even be limited to sentient beings - but would extend to entities as a whole. Heidegger enjoins us explicitly to "save the earth," i.e., in the face of modern technology and its subjugation of the planet to the status of gas station and warehouse, to allow entities to retain and reassert their darkness and density and reticence to disclosure, their 
"earthliness," as he puts it. In a technological age, Gelassenheit is above all a letting-be of the earthly.

"Earth" is for Heidegger not just, or even primarily, a planet in cosmic space, but rather the locus of closure and self-seclusion that Western metaphysics--and modern science and technology, to the extent that they are metaphysical successors-has tried to dominate. Earth is for each entity that element from which it emerges into appearance, and into which it continually withdraws. It is not only the "ground" in the literal sense of "soil" but also that which in every instance engenders what emerges: the earth is precisely that from which self-emergence arises, into which it continually withdraws, and which withholds and preserves the possibility of both. Viewed phenomenologically, it is the solidity of a colored object which can support a play of light and color only because of its very density and which can present one side of itself only by withholding another side from view. The earth is not only that in which plants take root and upon which houses are built but also human and animal bodies, the sound of a spoken word or the script of a written text, the bronze or clay which upholds a sculpted surface. In each case, the earth is what bears and gives rise to what comes to light only by remaining intrinsically dark itself. Earth is that which shelters and supports, "the serving bearer, blossoming and fruiting, spreading out in rock and water, rising up into plant and animal" (Heidegger, "Building, Dwelling, Thinking," p. 149). To save the earth is to allow to each and every entity the grounds for its own self-emergence. But this reticent self-emergence is the very phenomenon which, according to Heidegger, the early Greeks called physis! To save the earth, then, is to allow to each entity its "nature" in both dominant senses of the concept, "nature": both its characteristic way-to-be, and also its naturalness in emerging from itself, rather than emerging solely as the work of artifice or production. The mode of self-emergence of certain kinds of entities, however, is of special interest to us, attracting and arresting our attention. In $z o \hat{e}$, which we translate as "life," physis displays an intensified self-emerging, one that is not only a self-unfolding but also a self-opening that enters into the open alongside us.

But what then, specifically, about animals? Should we eat them? Or wear them? Or experiment on them? Or not? When these questions are juxtaposed alongside Heidegger's thoughts of "the earthly" and "selfemergence," the ontological violence of technological domination is brought to light as in almost no other instance. The food and apparel industries, as well as the mass use of animals in laboratories, are especially well-suited to illustrating the grim and uncanny power of technology as a manner of revealing entities and as a mode of comportment toward them: through these practices we can see most vividly what it means to say that technology violates the earthy self reserve, and hence the very nature, of beings over which it holds sway. Had we time today, a Heideggerean gloss (chapter by chapter) of Peter Singer's Animal Liberation would be most appropriate! What it would show, I believe, is that the impact of that book comes not primarily from the terrible animal suffering that it documents, for as critics such as J. Baird Callicott have been quick to note, animals suffer terribly in the wild as well. What is uniquely compelling in Singer's careful documentation of the technological processing of living beings is precisely the ontological horror which grips the reader, in the face of that very technological processing of life. Why is it that the suffering of the anemic and immobile veal calves induces in us a deep revulsion which all the combined PBS nature-show footage of predators tearing apart their prey could never come close to generating? Is it just the fact that humans, and not wolves or raptors, are in this case the agents of suffering and death? Or is it not more akin to the horror first evoked by Mary Shelley's novel, the horror at life usurped, mechanized, and appropriated-yet in this case without the frenzy of demented genius but, rather, arising from a comportment which takes upon itself nothing more demonic than the dull patina of business as usual and, thus, is all the more horrible.

Singer presents us with visions that provoke our outrage. He shows us, for example, vast, dimly lighted sheds with tens of thousands of chickens packed so tightly together in cages (as many as four or even five birds per square foot) that they are nearly immobile, and with all of their natural urges so entirely frustrated that they would turn to cannibalism were their beaks not already removed. If such practices resulted from negligence, or savage cruelty, we could at least understand them as deriving from human personality disorders, but in fact they are often the norm and result from openly espoused positions such as one that Singer cites from a British agronomy journal: "The modern layer is, after all, only a very efficient converting machine, changing the raw material-feedingstuffs—into the finished product - the egg-less, of course, maintenance requirements" (Animal Liberation, p. 103). Even more appalling are visions of 
laboratory studies and experiments in which mammals, and often primates, are coolly tortured to death or driven mad for the sake of findings so trivial that they possess utterly no interest for anything more than idle curiositylabs in which, as one horrified reporter put it, "the life of an animal has no meaning beyond the immediate purpose of experimentation" (Ibid., p. 63). "How," Singer asks, "can these things happen? How can a man who is not a sadist spend his working day heating an unanesthetized dog to death, or driving a monkey into a lifelong depression, and then remove his white coat, wash his hands, and go home to dinner with his wife and children?" (Ibid., p. 62).

Given Heidegger's critiques of modern science and technology, it is perhaps not saying enough to say that such practices are "wrong." Rather, they give us glimpses into the outer extremities of an ontological errancy become so total that it has lost touch entirely with any innocence in the face of being-has severed itself from any sense of delight in the self-emergence of the natural--so obsessed has it become with efficiency, and control, and explanation. What Heidegger allows us to see is that it is not enough to say, in good utilitarian fashion, that such practices result in needless pain for sentient sufferers. What, then, should be said, if it is not enough to say that such things are "wrong"? Already I have suggested that for Heidegger such things are "horrifying." But what is the horrifying? According to Heidegger, "the Horrifying [das Entsetzende] is that which sets "everything that is' outside of what was formerly its own way-to-be [Wesen or "nature" in the first sense noted above] "("The Thing," p. 166). Technology (whether in the laboratory or the factory farm or the totalitarian state or the modem war machine) sets upon entities to set them up as resources and raw materials, which it then sets in order for consumption and further production. But this is at the same time horrifying: "everything that is"--people, animals, lands and seas, subatomic particles and genetic codes-gets "set outside of," displaced from, or stripped of what was before this its own mode of self-emergence, its very nature. (For those who have not read Singer's book, I can relay to you that his discussion of Harlow's experiments on primates with maternal deprivationcomplete with "monster mothers" who brutalize and murder their trusting charges-raises horror to levels usually attained only in the cinema.)

What about the animals? Should we eat them? Or wear them? Or experiment on them? I think the only consistent answer, deriving from Heidegger's approach, is: given the way we typically go about doing these things, no! One of the most notable features of Singer's book is its effectiveness in demonstrating how trivial are the gains to be obtained by all this suffering and horror: how trivial the experimental results, how petty the decrease in the cost of eggs, how easily more decent methods could be implemented. This is not only material for a utilitarian calculus: perhaps more importantly, it is significant evidence that Heidegger is right in his claim (reiterated recently by Thomas Berry in his book, The Dream of the Earth) that we are bewitched and enchanted by modern technology, that we look to it for our salvation, that efficiency and domination and control are pursued blindly at any cost, and right that we need to let go of this obsession.

But what about gentler, more merciful ways of raising animals or more intelligent and significant and compassionate experiments than really might teach us something? Here is where, I believe, Heidegger leaves us on our own. We are, let us now grant, to let animals be, allow them to enter into the full display of their own ways to be, let them come into appearance from themselves, without betraying their inherent selfwithholding. Who, then, lets them be, and who does not? Not the agribusiness entrepreneur nor the glib researcher nor even the administrators at my own College who remove alligators from the ponds when they reach a certain size, for to let an alligator "be" is surely to let it be ... dangerous. But I see no way, from Heidegger's point of view, to maintain that no human use of animals lets them be. On the contrary, the reverent and risky right of passage in which a Native American youth procures an eagle feather seems to me to let the eagle show forth its own splendor just as much as does the awe of the Audobon Society observer. That we are at long last replenishing some of our wild areas with wolves seems to be a most wonderful letting-be of canine physis but so, too, is the very evident zest and exuberance with which a dog performs extraordinary tricks for its trainer. Heidegger leaves us here to work out our relation to animals historically, as our own wayto-be unfolds alongside theirs, and relative to our own cultural sensibilities and intuitions, and, of course, our customs regarding cruelty and compassion. What I have called his onto-ethical imperative is, it seems to me, capable of many sorts of elaborations, and it is in this sense that I believe it is meaningful to say that Heidegger is an historicist. 


\section{Does It Take an Animal to Be Good to One?}

There is, however, a final issue to be confronted concerning the bearing of Heidegger's thought on our treatment of animals. Contrary to most environmentalists and animal right activists, who feel that it is important to see humanity as an animal species, Heidegger rejects human animality altogether. And contrary to an even larger number, rather than seeing human beings as simply component parts of nature, he sees them as those beings through whom (but not necessarily, I want to add immediately, for the sake of whom) nature comes to light and emerges into presence. Since Heidegger has come under some recent criticism for these views, it seems worthwhile to pose the question explicitly: is there a clear and direct relationship, as it is often assumed, between how we treat animals and whether-or the extent to which-we see ourselves as animals?

To respect and/or treat well members of class $\Sigma$, it is held, one must oneself be - or see oneself as-a member of $\sum$. But from this, it would follow that to respect the French, I would need to be French as well; to treat babies well and respect them, I would have to be a baby (or at least see myself as one); to respect works of art or treat them well, I must myself be a work of art, and so on for shop tools, African violets, or Siamese cats and Bengal tigers. But since this is so clearly absurd, we must ask why this kind of assumption prevails at all. Surely there must be some other reasoning underlying this widespread claim and belief.

There are grounds for believing that it has evolved from a peculiar extension of thinking about interracial justice. (Indeed, Aldo Leopold--patron of deep ecology-draws heavily on this analogy). If I deny to members of other races the status of being human, then I am likely (indeed, certain!) to mistreat them. And the same goes, it might be said, for my beliefs about members of other species: if I deny an identity with them, then here, too, it seems I will be prone to mistreat them-and in fact, as would be the case with my beliefs about other races, the suspicion would arise that my belief is held precisely in order to $j u$ stify my mistreating them. But this only seems to make sense. Members of other races precisely are human and deserving of whatever any human deserves, while animals simply are not human and in fact represent in the analogy just that status which it would be wrong to accord members of other races. It could, of course, be argued that what justice requires is not a so-called promotion of animals to human status but a de facto demotion of human beings to animal status. But in that case, demands for racial justice (viz., demands to be accorded as fully human) would become incoherent.

Finally, taken simply as an empirical claim, it is questionable to state that class identity (I mean here, of course, ontical and logical class) precludes mistreatment. On the contrary, civil wars are typically more merciless than wars between nations; gang violence (generally between members of the same race, socio-economic group, and neighborhood) is unusually brutal; and domestic violence (i.e. within the family, where group identity is at its highest and least controversial) often reaches alarming intensity and, in fact, accounts for a large portion of all violence in society.

To say simply that people are animals is, I believe, of no necessary help to the animals themselves. Yet neither I-nor, I think, Heidegger-would maintain an utter discontinuity. I experience both within myself as well as without that physis rises up always out of the darkness of earth. In both cases it commands respect if I allow it to be what it is, and it is just this letting-be that Gelassenheit prescribes. And I do not see how it is possible to respect this within, yet not without-or vice versa.

So, in summary:

Against the Western view that explicability and calculability are the salient characters of the real, Heidegger maintains that more primary is a selfconcealing and self-withdrawing character, i.e.. that being is better grasped as also inherently "mysterious" than as purely intelligible. He understands nature not solely as mechanism but in terms of the Greek physis or "self-witholding self-emergence," that which come forth and recedes of its own accord, and understands life as $z o \hat{e}$, "intensified self-emergence." The attunement to this sense of being engenders respect and even reverence for living things. Such an attunement is not unlike the relation of many indigenous peoples, such as Native Americans, to both domestic and wild animals: even when their treatment of animals is harsh, it is never lacking in respect for the mystery that is at play in all life. Yet Heidegger arrives at this position from a critique of Western thought and practice that is entirely immanent and, hence, accessible to us in ways that non-Western views may never be. 